\title{
MORFOLOGIA DE FRUTOS, SEMENTES E PLÂNTULAS E GERMINAÇÃO DE SEMENTES DE Erythrina variegata $\mathbf{L} .^{1}$
}

\author{
MIELE TALLON MATHEUS², JOSÉCARLOS LOPES ${ }^{3}$
}

\begin{abstract}
RESUMO - A caracterização morfológica de frutos e sementes fornece subsídios para diferenciar espécies e caracterizar aspectos ecológicos da planta, como a dispersão, estabelecimento de plântulas e fase da sucessão ecológica. São poucos os estudos sobre Erythrina variegata L. e na literatura não há informações sobre seu comportamento, principalmente sobre seu sistema de propagação no Estado do Espírito Santo. Objetivou-se estudar a morfologia de frutos, sementes e plântulas desta espécie, caracterizando-se os frutos externamente, as sementes interna e externamente e os processos de desenvolvimento e de diferenciação dos estádios das plântulas, além de se obter informações sobre a germinação das sementes, submetidos aos tratamentos de escarificação mecânica com lixa d'água ${ }^{\circ} 120$, do lado oposto ao embrião; escarificação com lixa e posterior embebição em água à temperatura ambiente por 6, 12 e 24 horas; choque térmico; e embebição em água à temperatura ambiente por 12 e 24 horas. As sementes não se mostraram impermeáveis à entrada de água através dos tegumentos, dispensando a adoção de tratamentos pré-germinativos.
\end{abstract}

Termos para indexação: Caracterização morfológica, dormência, propagação de plantas.

\section{FRUIT, SEED AND SEEDLING MORPHOLOGY AND SEED GERMINATION OF Erythrina variegata L.}

\begin{abstract}
Morphological characterization of fruits and seeds provides subsidies for species differentiation and characterization of ecological aspects of plants, such as dispersion, seedling establishment and ecological succession phase. Thereare few studies reported in regard to Erythrina variegata L. and in the literature there is no information about its behavior, especially about its system of propagation in the State of Espírito Santo. The objective of this study was to investigate the morphology of the fruits, seeds and seedlings of this species, characterizing the fruits externally, the seeds internally and externally, and describing the process of development and differentiation of the phases of the seedlings, as well as collecting information regarding the seed germination, using a completely randomized experimental design with the following treatments: intact seeds (control); mechanical scarification with sandpaper number 120, on the opposite side to the embryo; scarification with sandpaper and posterior soaking in water at ambient temperature for 6, 12 and 24 hours; thermal shock; and soaking in water at ambient temperature for 12 and 24 hours. The seeds did not show themselves impermeable to water through their teguments, thus, not requiring pre-germination treatments.
\end{abstract}

Index terms: morphological characterization, dormancy, plant propagation.

\footnotetext{
1 Submetido em: 17/08/2006 Aceito para publicação em: 21/02/2007. Parte da Dissertação de Mestrado e agradecimentos à CAPES pela concessão de bolsa ao primeiro autor.

2 Engenheiro Florestal, aluno do Programa de Pós-graduação em Produção Vegetal, bolsista CAPES, CCA-UFES, Cx. Postal 16, CEP 29500-000, Alegre-ES, miele-mpv@cca.ufes.br

3 Engenheiro Agrônomo, Dr., Prof. Associado, Departamento de Produção Vegetal, Centro de Ciências Agrárias (CCA) - UFES - Campus de Alegre, Cx. Postal 16, CEP 29500-000, Alegre-ES, jclopes@ cca.ufes.br
} 


\section{INTRODUÇÃO}

A eritrina indiana, Erythrina variegata L., é uma árvore Leguminosae-Papilionoideae, de 15-20 metros de altura, nativa nas regiões costeiras da Índia e Malásia. É empregada em muitos países tropicais como forrageira, para a formação de quebra-ventos, para a produção de madeira leve e para polpa celulósica, além de possuir características ornamentais notáveis, podendo ser aproveitada para uso paisagístico em geral (Lorenzi et al., 2003). Segundo Matos et al. (2005), esta espécie vem sendo pesquisada visando seu plantio para produção de moirões vivos e construção de cercas ecológicas. Entretanto, o sucesso na germinação e desenvolvimento de uma espécie em um determinado ambiente depende, em parte, da energia utilizada na sua biologia reprodutiva, como na polinização, produção de sementes, dispersão e estabelecimento das plântulas; além de existir uma forte relação entre o peso médio das sementes e o porte da espécie (Baker, 1972).

Estudos que visam o conhecimento da morfologia de frutos e sementes de espécies arbóreas são ainda escassos na literatura referencial, tendo como exemplos os trabalhos de Ferreira et al. (1998) com Dipteryx alata Vog.; Cruz e Carvalho (2003) com Micropholis venulosa Mart. \& Eichler; Silva et al. (2003) com Bauhinia forficata Link; Melo et al. (2004) com Hymenaea intermedia var. adenotricha (Ducke) Lu \& Lang.; Abreu et al. (2005a) com Allophylus edulis (St.-Hil.) Radlk.; Abreu et al. (2005b) com Drimys brasiliensis Miers. e Añez et al. (2005) com a espécie medicinal Jatropha elliptica Müll. Arg. Estudos envolvendo análise morfológica de frutos e sementes podem auxiliar no entendimento do processo de germinação, vigor, armazenamento, viabilidade e métodos de propagação das espécies. Além disso, a caracterização morfológica de frutos e sementes fornece subsídios para diferenciar espécies e caracterizar aspectos ecológicos da planta, como a dispersão, estabelecimento de plântulas e fase da sucessão ecológica. Para Piña-Rodrigues et al. (1990), o potencial de estabelecimento de uma população em um habitat é essencialmente controlado pelo fluxo de propágulos. Entretanto, sabe-se que o tamanho dos frutos e sementes, além de outras formas de atração, como cheiro e cor, é um dos fatores que podem influenciar a dispersão dos propágulos, uma vez que, conforme tais autores, o tamanho do fruto e da semente está diretamente relacionado com a quantidade de reservas armazenadas nos tecidos e sua atratibilidade e funcionalidade em relação aos agentes dispersores.

A maioria das sementes de espécies florestais germina quando é colocada em condições ambientais que lhe é favorável. Nestas condições, quando a germinação não ocorre, as sementes são consideradas dormentes (Bianchetti, 1981). As sementes de muitas espécies florestais apresentam restrições à passagem de água através do tegumento, principalmente sementes das leguminosas, fenômeno que é controlado geneticamente, variando entre espécies, variedades e sofrendo influência das condições ambientais durante a maturação e o armazenamento das mesmas. A germinação pode ser definida como uma série seqüencial de eventos morfogenéticos que resultam na transformação de um embrião em uma plântula. Entretanto para que ela ocorra, é necessário além do substrato, que haja disponibilidade de água em níveis ideais, de acordo com o tipo de semente, composição de gases e temperaturas adequadas. Além de luz, exigida para certas espécies, que a semente seja viável, isto é, que o embrião esteja vivo e capaz de germinar e que esteja no estado quiescente, de tal forma que quando submetida a condições de ambiente ideais, ela germine (Mayer e Poljakoff-Mayber, 1989). O aumento da porcentagem de germinação, bem como sua aceleração e uniformidade, são os objetivos da quebra de dormência de sementes. Esta, por sua vez, constitui um sério problema por ocasião da semeadura pela irregularidade na germinação afetando a homogeneidade das plântulas e o tempo de formação das mudas (Souza et al., 1994).

Os conhecimentos sobre Erythrina variegata, são incipientes e na literatura não há informações sobre seu comportamento, principalmente sobre seu sistema de propagação no Estado do Espírito Santo, motivos que objetivaram desenvolver o presente estudo, para conhecer a morfologia dos frutos e sementes e a viabilidade de sua propagação sexual, para subsidiar produção de mudas e auxiliar na dispersão da espécie.

\section{MATERIAL E MÉTODOS}

\section{Coleta dos frutos}

Os frutos maduros de Erythrina variegata foram coletados na copa de três matrizes existentes às margens 
da rodovia no município de Vila Velha, estado do Espírito Santo, com latitude de $20^{\circ} 20^{\prime} 12^{\prime \prime} \mathrm{S}$ e longitude de $40^{\circ} 17^{\prime} 28^{\prime \prime} \mathrm{W}$, $4 \mathrm{~m}$ de altitude e clima tropical litorâneo, no período de novembro a dezembro de 2005 e levados para o Laboratório de Análise de Sementes do Centro de Ciências Agrárias da Universidade Federal do Espírito Santo (CCA-UFES), em Alegre-ES, para condução dos estudos.

Imediatamente após a coleta e extração das sementes, foi avaliado o teor de água inicial das sementes, pelo método de estufa a $105^{\circ} \pm 3^{\circ} \mathrm{C}$ por 24 horas (Brasil, 1992).

\section{Caracterização morfológica do fruto e da semente}

No estudo das características externas, foram utilizadas oito repetições de 20 frutos e de 20 sementes para as avaliações. Foram descritas as características botânicas, o comprimento, largura e espessura, com auxílio de uma régua milimetrada e um paquímetro com precisão de $0,1 \mathrm{~mm}$. $\mathrm{O}$ comprimento foi medido da base até o ápice, excluindo-se o pedúnculo, e a largura e espessura foram medidas na linha mediana dos frutos e sementes. A remoção das sementes de cada fruto foi feita manualmente com o auxílio de uma lâmina.

Para a caracterização interna das sementes, utilizou-se 20 sementes. Conforme metodologia adotada por Silva e Matos (1991) para Erythrina velutina, as sementes foram imersas em água destilada por 24 horas e fervidas por 10 minutos para amolecimento dos tegumentos. As seções longitudinais e transversais foram feitas, exatamente, na porção mediana das sementes (Groth e Liberal, 1988), utilizando-se bisturi, visando-se a adequada observação do embrião. As descrições foram feitas com auxilio de uma lupa.

\section{Caracterização de plântulas e da germinação}

Para avaliar a ocorrência de fotoblastismo, colocou-se 15 sementes para germinar sobre papel de filtro, em placa de Petri, em germinador na temperatura constante de $30^{\circ} \mathrm{C}$, no escuro e sob luz branca 8-16 horas luz/escuro, sendo a avaliação da germinação feita sob luz verde. A caracterização da germinação e descrição morfológica das plântulas foi feita semeando-se 20 sementes em caixa "gerbox" contendo areia de rio lavada e esterilizada como substrato, em germinador na temperatura constante de $30^{\circ} \mathrm{C}$ e fotoperíodo 8-16 horas luz/escuro (exceto para a avaliação da emergência da radícula). As sementes germinadas foram selecionadas e transferidas para copos individuais contendo água destilada, para descrição das fases de germinação. Seguindo-se a metodologia utilizada por Silva e Matos (1991) com sementes de Erythrina velutina, foram descritos os processos de desenvolvimento e de diferenciação dos estádios, por meio de observações diárias, para descrição morfológica das plântulas. A primeira fase foi caracterizada pelo intumescimento da semente até o aparecimento da radícula. Dada a dificuldade de se observar essa fase em areia, 20 sementes foram mantidas sobre papel de filtro, em placa de Petri, em germinador a $30^{\circ} \mathrm{C}$ e fotoperíodo 816 horas luz/escuro. Na segunda fase, foi considerada a emissão dos cotilédones, sem a formação dos protófilos. $\mathrm{Na}$ terceira, os protófilos formados caracterizaram a plântula normal.

\section{Peso de mil sementes e número de sementes por quilograma}

Os testes físicos foram feitos segundo as recomendações das Regras para Análise de Sementes, utilizando-se oito repetições de 100 sementes (Brasil, 1992). Foram determinados ainda o número de sementes por fruto e a porcentagem de sementes chochas.

\section{Germinação das sementes}

As sementes foram extraídas manualmente dos frutos, mantidas em geladeira a $3 \pm 1^{\circ} \mathrm{C}$ durante 28 dias, e posteriormente colocadas para germinar. Os tratamentos adotados para avaliação da capacidade germinativa das sementes foram sementes intactas (controle); escarificação mecânica com lixa d' água ${ }^{\circ} 120$ no lado oposto ao embrião; escarificação com lixa e posterior embebição em água à temperatura ambiente por 6, 12 e 24 horas; choque térmico, mantendo-se as sementes imersas em água a aproximadamente $80^{\circ} \mathrm{C}$ por três minutos e posterior imersão e lavagem com água da torneira; e embebição em água à temperatura ambiente por 12 e 24 horas. Utilizaram-se quatro repetições de 10 sementes por tratamento. A semeadura foi feita em sacolas de polietileno de $11 \mathrm{x} 13 \mathrm{~cm}$, contendo substrato comercial "Solomax" (Eucatex), a 1,5cm de profundidade, que foram mantidas em ambiente natural, com $50 \%$ de sombra. As irrigações foram feitas diariamente, de acordo com as necessidades apresentadas. Os 
parâmetros avaliados foram a germinação total, velocidade de emergência (Maguire, 1962) e desenvolvimento das plântulas durante o estádio inicial até 31 dias após a semeadura. Foram feitas medições do diâmetro do coleto, com paquímetro, e da altura das plântulas, do coleto até a inserção da folha mais nova, com auxílio de uma régua milimetrada. Foram consideradas germinadas as sementes que apresentaram todas as estruturas normais (raiz primária, hipocótilo, cotilédones, epicótilo e protófilos). Os resultados de germinação, obtidos em porcentagem, foram transformados em arco seno da raiz quadrada da \%/100 e, os dados de índice de velocidade de emergência, em raiz de $(X+0,5)$ e, posteriormente, submetidos à análise de variância, com a comparação das médias pelo teste de Tukey, a 5\% de probabilidade, com o auxílio do software SAEG 7.1 (SAEG, 1997).

\section{RESULTADOS E DISCUSSÃO}

O uso de alguns termos referentes à análise morfológica dos frutos, sementes e plântulas foi baseado em Groth e Liberal (1988); Silva e Matos (1991); Barroso et al. (1999) e Vidal e Vidal (2003).

Conforme Figura 1, Erythrina variegata apresenta frutos do tipo legume, cilíndricos e curvilíneos, concordando com o citado por Lorenzi et al. (2003), polispérmicos, com constrição entre os lóculos, de pericarpo seco, deiscentes, que apresentam tamanhos variados, coloração verde na fase de crescimento e marrom-escuro quando maduros. Persistentes, que permanecem sobre a árvore durante alguns meses. O comprimento médio é de $14,83 \mathrm{~cm}$ (variando de 6,40 a 25,40cm); largura média de $1,69 \mathrm{~cm}(1,00$ a 2,10cm) e espessura média de $1,50 \mathrm{~cm}(0,80$ a $1,80 \mathrm{~cm})$ conforme Tabela 1. O comprimento e a largura dos frutos avaliados corroboram as informações de Lorenzi et al. (2003), cujos intervalos variam de 15 a $20 \mathrm{~cm}$ e de 1,50 a $2,00 \mathrm{~cm}$, respectivamente. Os resultados das análises dos frutos e das sementes de Erythrina variegata (Figura 2) evidenciaram que a maioria dos frutos desta espécie apresentou comprimento variando entre 14,00 e 17,99cm; largura de 1,60 a $1,89 \mathrm{~cm}$ e a espessura de 1,40 a $1,69 \mathrm{~cm}$. As sementes apresentaram em média 1,40 a $1,59 \mathrm{~cm}$ de comprimento, 0,90 a $1,09 \mathrm{~cm}$ de largura e 0,90 a $1,09 \mathrm{~cm}$ de espessura.

De acordo com a Figura 1, semente madura de reniforme a elíptica; com comprimento médio de $1,42 \mathrm{~cm}$ (variando de 1,00 a 1,70cm); largura média de $0,87 \mathrm{~cm}(0,70$ a $1,20 \mathrm{~cm})$ e espessura média de $0,90 \mathrm{~cm}(0,50$ a $1,40 \mathrm{~cm})$, conforme Tabela 1. A massa fresca de uma semente, em média, é $0,64 \mathrm{~g}$ e, a massa seca, $0,58 \mathrm{~g}$, correspondendo a cerca de $10 \%$ de umidade. Tegumento córneo com superfície lisa e brilhante, de coloração castanho-clara a castanho-arroxeada; hilo elíptico, castanho-escuro, em média $6,90 \mathrm{~mm}$ de comprimento no sentido longitudinal da semente e 3,1mm de largura, apresenta depressão na porção mediana e halo branco-gelo; micrópila circular, de coloração amarelo-ocre, com diâmetro de 1,0 a 2,0mm; rafe suborbicular, marrom-escura e diâmetro de 1,0 a $1,5 \mathrm{~mm}$. A semente é bitegumentada, com tegumentos fortemente aderidos aos cotilédones. Embrião axial, invaginado, com dois cotilédones plano-convexos, opostos e iguais, semielípticos, lisos, carnosos e de coloração branco-amarelada; e eixo hipocótilo-radícula curto, infletido, localizado lateralmente e de coloração branco-amarelada.

TABELA 1. Dados biométricos de frutos e sementes de Erythrina variegata L. Laboratório de Sementes, CCA - UFES. Alegre-ES, 2006.

\begin{tabular}{lcrr}
\hline & Mínimo & Média $\pm \boldsymbol{\sigma}$ & Máximo \\
\hline Fruto & & & \\
Comprimento $(\mathrm{cm})$ & 6,40 & $14,83 \pm 3,38$ & 25,40 \\
Largura $(\mathrm{cm})$ & 1,00 & $1,69 \pm 0,17$ & 2,10 \\
Espessura $(\mathrm{cm})$ & 0,80 & $1,50 \pm 0,21$ & 1,80 \\
Semente & & & 1,70 \\
Comprimento $(\mathrm{cm})$ & 1,00 & $1,42 \pm 0,13$ & 1,20 \\
Largura $(\mathrm{cm})$ & 0,70 & $0,87 \pm 0,08$ & 1,40 \\
Espessura $(\mathrm{cm})$ & 0,50 & $0,90 \pm 0,09$ & \\
\hline
\end{tabular}



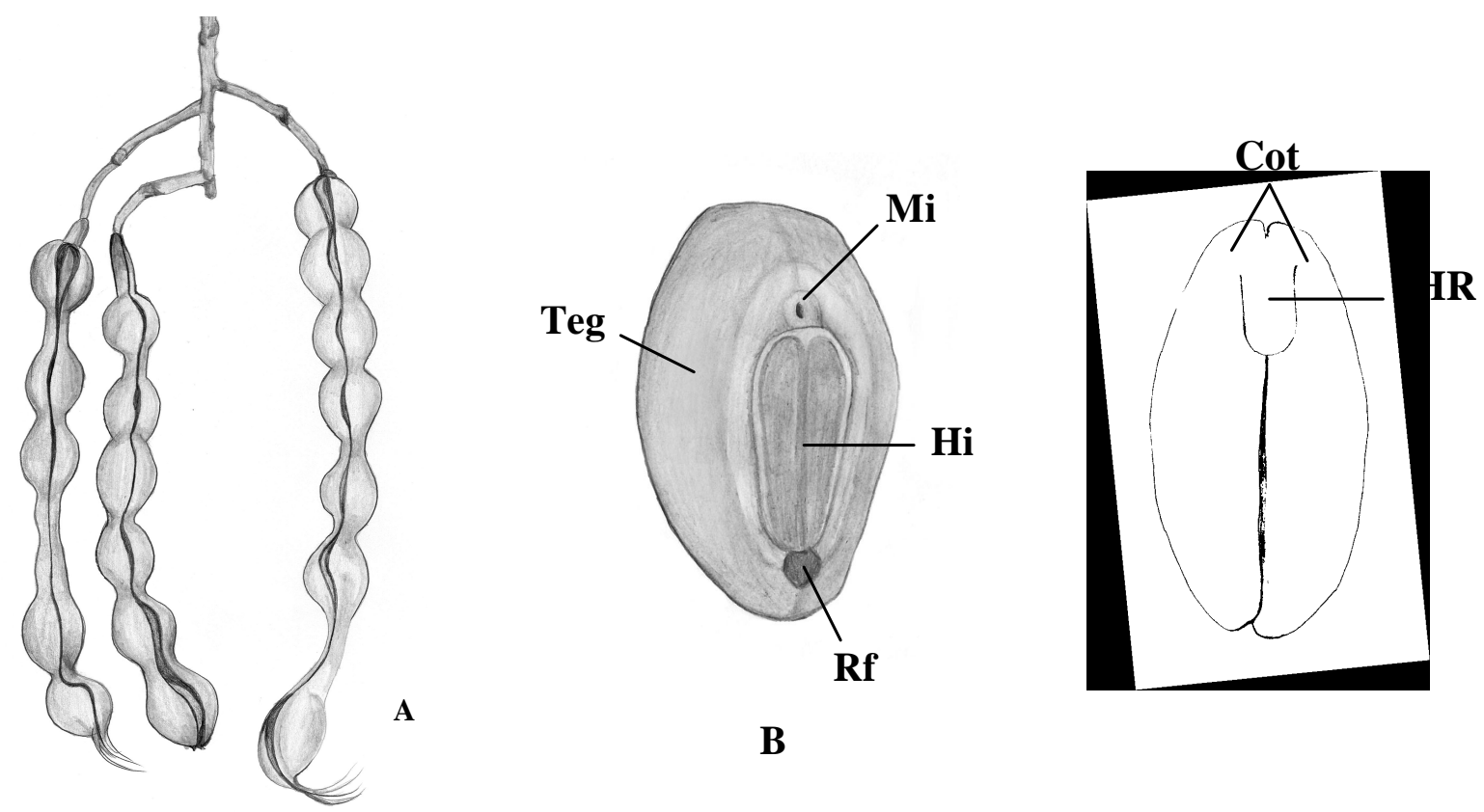

FIGURA 1. A - frutos; B - vista externa da semente; C - vista interna da semente. Laboratório de Sementes, CCA - UFES. Alegre-ES, 2006.

Legenda: Teg - tegumento; Hi - hilo; Mi - micrópila; Rf - rafe; Cot - cotilédone; HR - eixo hipocótilo-radícula.

A germinação foi caracterizada como epígea (Figura 3), fanerocotiledonar e as sementes não apresentam fotoblastismo. Na primeira fase da germinação, com 24 horas as sementes já se encontravam intumescidas, sendo que se evidenciou a emergência da radícula após três dias do início do experimento. A radícula, de coloração branca, rompeu o tegumento no sentido transversal, próximo ao hilo.

A segunda fase ficou evidenciada pela emissão dos dois cotilédones aderidos ao tegumento, seis dias após a montagem do experimento. Cotilédones opostos iguais, com 1,9 a $2,1 \mathrm{~cm}$ de comprimento por 1,0 a $1,2 \mathrm{~cm}$ de largura, carnosos, glabros, amarelados (variando para esverdeado à medida que se aproxima do hipocótilo). Hipocótilo verdeesbranquiçado, cilíndrico, glabro, com 1,6 a $3,1 \mathrm{~cm}$ de comprimento por 0,3 a $0,4 \mathrm{~cm}$ de diâmetro. Colo bem delimitado e com coloração esbranquiçada. Raiz primária axial branco-parda, sinuosa, de 2,8 a $4,8 \mathrm{~cm}$ de comprimento e com poucos primórdios de raízes secundárias brancas.

A terceira fase se caracterizou pela emissão dos protófilos, que ocorreu nove dias após o início do experimento. As plântulas apresentavam raiz principal branco-amarelada, sinuosa, variando de 5,1 a $8,0 \mathrm{~cm}$ de comprimento; raízes secundárias bem evidentes e numerosas, com 0,7 a 2,1cm de comprimento e de coloração branca; colo bem delimitado, de coloração esbranquiçada e levemente curvo; hipocótilo verde-claro, com 4,0 a $6,9 \mathrm{~cm}$ de comprimento e 0,3 a $0,4 \mathrm{~cm}$ de diâmetro, glabro e cilíndrico; dois cotilédones opostos, iguais, persistentes, carnosos, glabros, sésseis, verde-claros, com 1,9 a 2,1cm de comprimento por 0,6 a $0,7 \mathrm{~cm}$ de largura cada um e tegumento não mais aderido; epicótilo verde, cilíndrico, com 1,5 a 1,7cm de comprimento; protófilos com o primeiro par oposto, glabro, verde, com 0,4 a 0,6 cm de comprimento, de sagitado a cordiforme e peciolado; pecíolo verde, medindo entre 0,4 e $0,5 \mathrm{~cm}$ de comprimento, com presença de um par de estípulas verdes, opostas, lanceoladas e separadas por uma gema vegetativa de coloração verdeesbranquiçada.

As características físicas das sementes encontram-se na Tabela 2. Destaca-se o número de sementes encontradas por vagem, que foi de cinco (variando de uma a nove sementes), discordando de Lorenzi et al. (2003), que citam que o número de sementes por vagem varia de cinco a 10 . As diferenças podem estar associadas às diferenças ambientais e às diferenças genéticas das populações. 

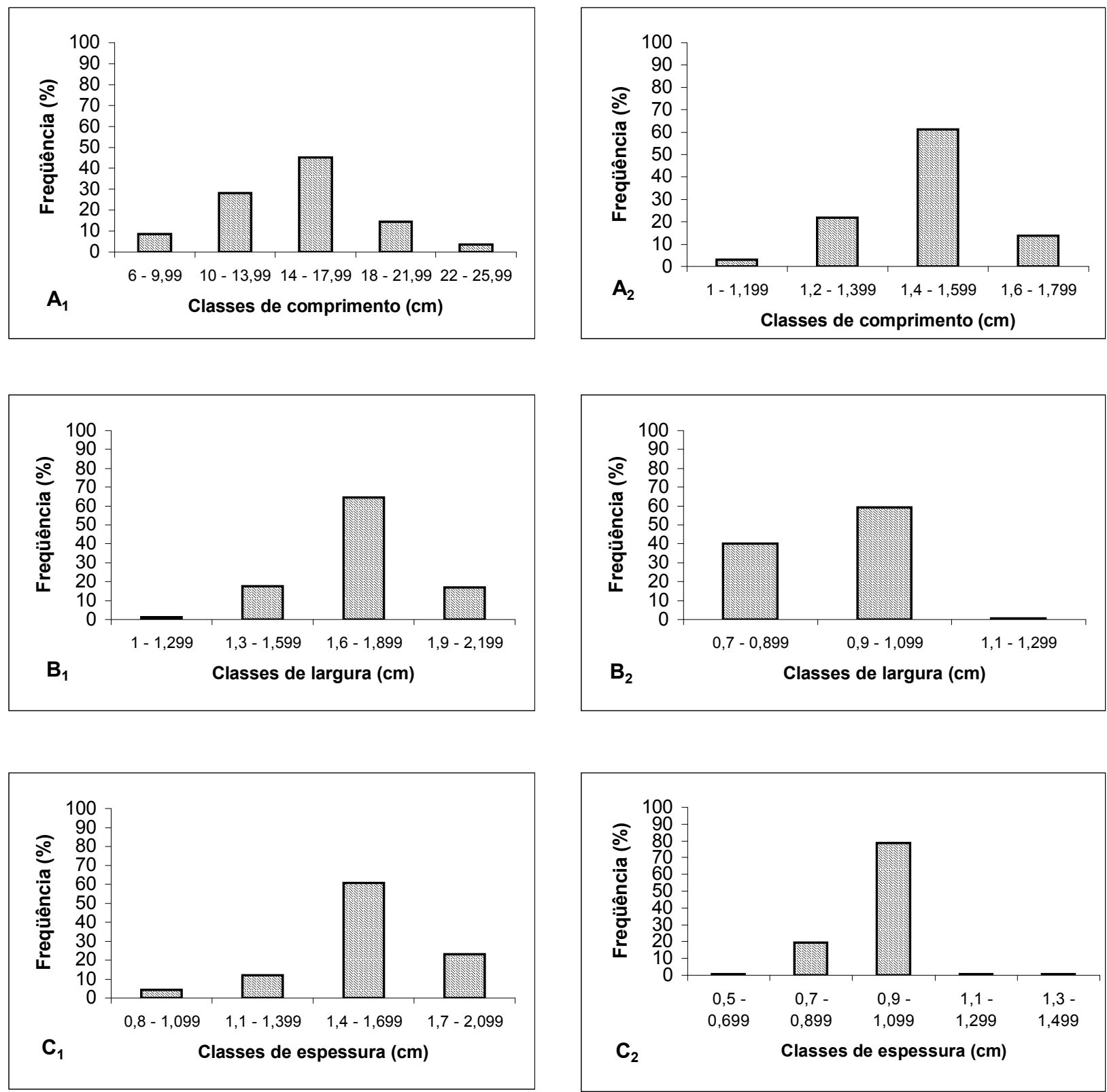

FIGURA 2. Freqüência de frutos e sementes, respectivamente, de Erythrina variegata $\mathrm{L}$. em cada classe de comprimento ( $A_{1}$ e $A_{2}$ ), largura $\left(B_{1}\right.$ e $\left.B_{2}\right)$ e espessura $\left(C_{1}\right.$ e $\left.C_{2}\right)$. Laboratório de Sementes, CCA - UFES. Alegre-ES, 2006. 
TABELA 2. Características físicas da semente de Erythrina variegata L. Laboratório de sementes, CCA - UFES. Alegre-ES, 2006.

\begin{tabular}{lc}
\hline \multicolumn{1}{c}{ Características } & Valores \\
\hline Umidade (\%) & 10,00 \\
Peso de mil sementes $(\mathrm{g})$ & 570 \\
Número de sementes/kg & 1.754 \\
Número de sementes/fruto & $5 \pm 1,78$ \\
\hline
\end{tabular}

O número médio de sementes chochas foi de 0,23 por fruto ou, em média, $4,6 \%$ por fruto.

Os resultados do teste de germinação para sementes de Erythrina variegata após os tratamentos encontramse na Tabela 3. O melhor resultado foi no tratamento com sementes escarificadas ( $85 \%$ de germinação e IVE=1,037), embora não haja diferença significativa entre este tratamento e o da escarificação e posterior embebição durante seis horas $(78 \%$ de germinação e IVE=0,872). De modo especial, entre estes e a testemunha $(80 \%$ de germinação e IVE=0,754). Entretanto, esses três tratamentos diferiram significativamente dos demais, tanto na germinação total quanto no vigor, avaliado através do índice de velocidade de emergência. Os tratamentos com escarificação seguida de embebição mostraram-se eficientes apenas para tempos menores de imersão em água, uma vez que a embebição por tempo mais prolongado determinou redução significativa na porcentagem final de germinação (Figura 4) e no índice de velocidade de emergência (Tabela 3). Quando estes caíram, por exemplo de $85 \%$ e 1,037 nas sementes com tempo zero de embebição, para $23 \%$ e 0,282 , respectivamente, nas que embeberam por 24 horas após escarificação mecânica. Este decréscimo na germinação se atribui ao excesso de água, possivelmente absorvido durante o período de embebição, uma vez que Borges e Rena (1993) salientam que o excesso de umidade, em geral provoca decréscimo na germinação, visto que impede a penetração do oxigênio e reduz todo o processo metabólico resultante. A utilização dos tratamentos de choque térmico e embebição por 12 e 24 horas em água não se mostrou viável para as sementes desta espécie. Para Erythrina velutina, Fowler e Bianchetti (2000) recomendam a escarificação mecânica por cinco segundos para elevar a germinação. Pelos resultados, percebe-se ser desnecessário a adoção de tratamentos de quebra de dormência para a germinação das sementes de Erythrina variegata, pois a taxa de germinação e velocidade de emergência observadas nos tratamentos mais eficientes mostraram-se estatisticamente equivalentes à testemunha. Com exceção dos tratamentos de embebição por 12 e 24 horas, os demais tratamentos favorecem o crescimento médio em altura das plântulas. Já a espessura média dos coletos das plântulas de cada tratamento não apresentou diferença significativa.

TABELA 3. Germinação (\%), índice de velocidade de emergência (IVE), altura (cm por planta) e diâmetro médio por plântula $(\mathrm{cm})$ de Erythrina variegata L. após tratamentos pré-germinativos. Laboratório de Sementes, CCA - UFES. Alegre-ES, 2006.

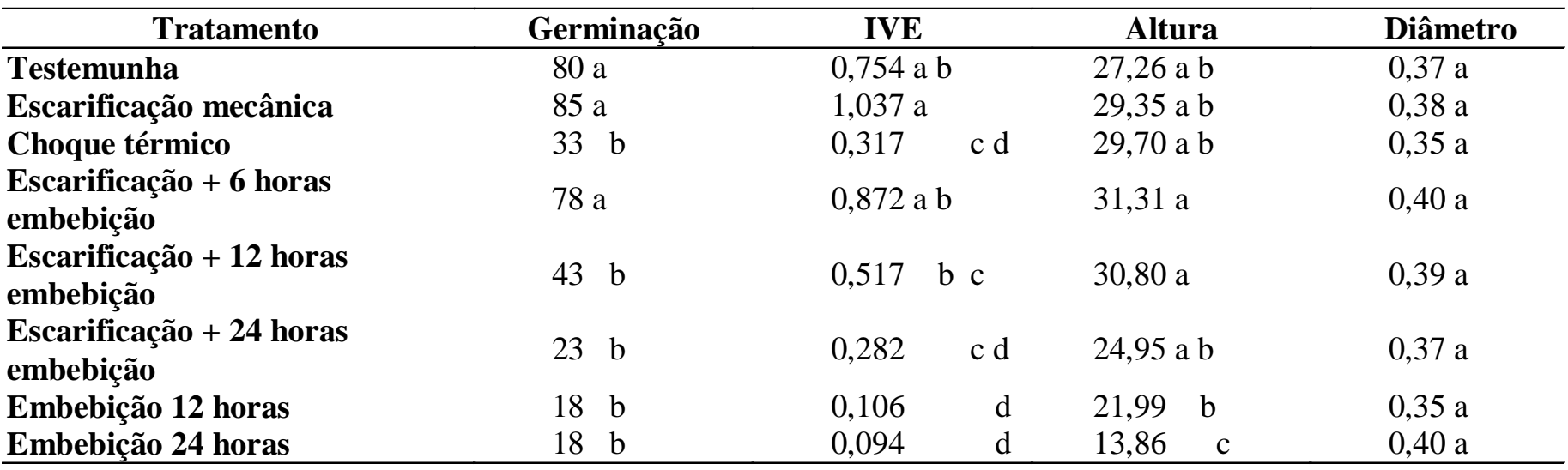



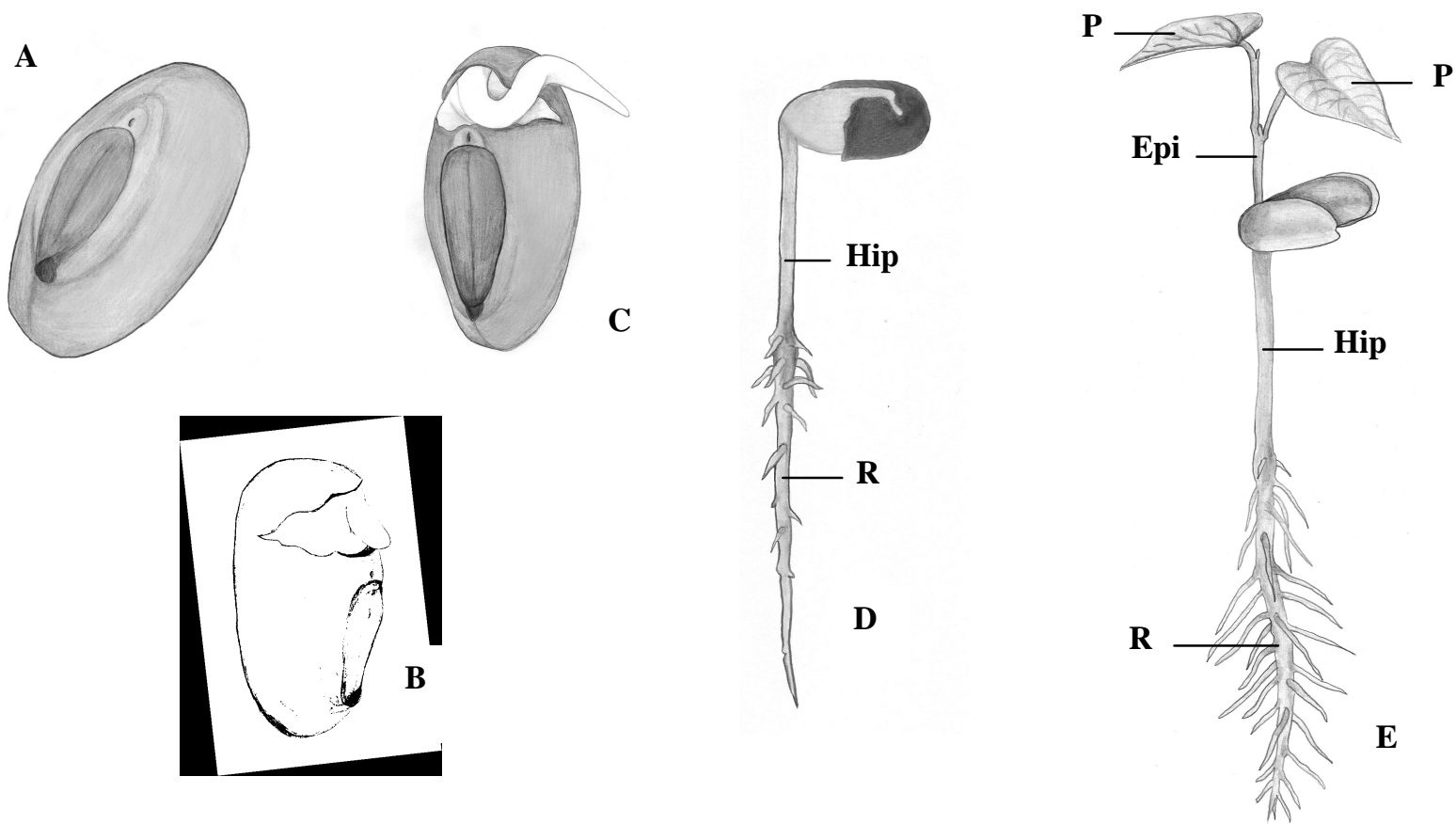

FIGURA 3. A - semente intumescida; B - rompimento do tegumento; C - protrusão da radícula; D - emissão dos cotilédones; E - emissão dos protófilos. Laboratório de Sementes, CCA - UFES. Alegre-ES, 2006. Legenda: Hip - hipocótilo; R - raiz; P - protófilo; Epi - epicótilo.

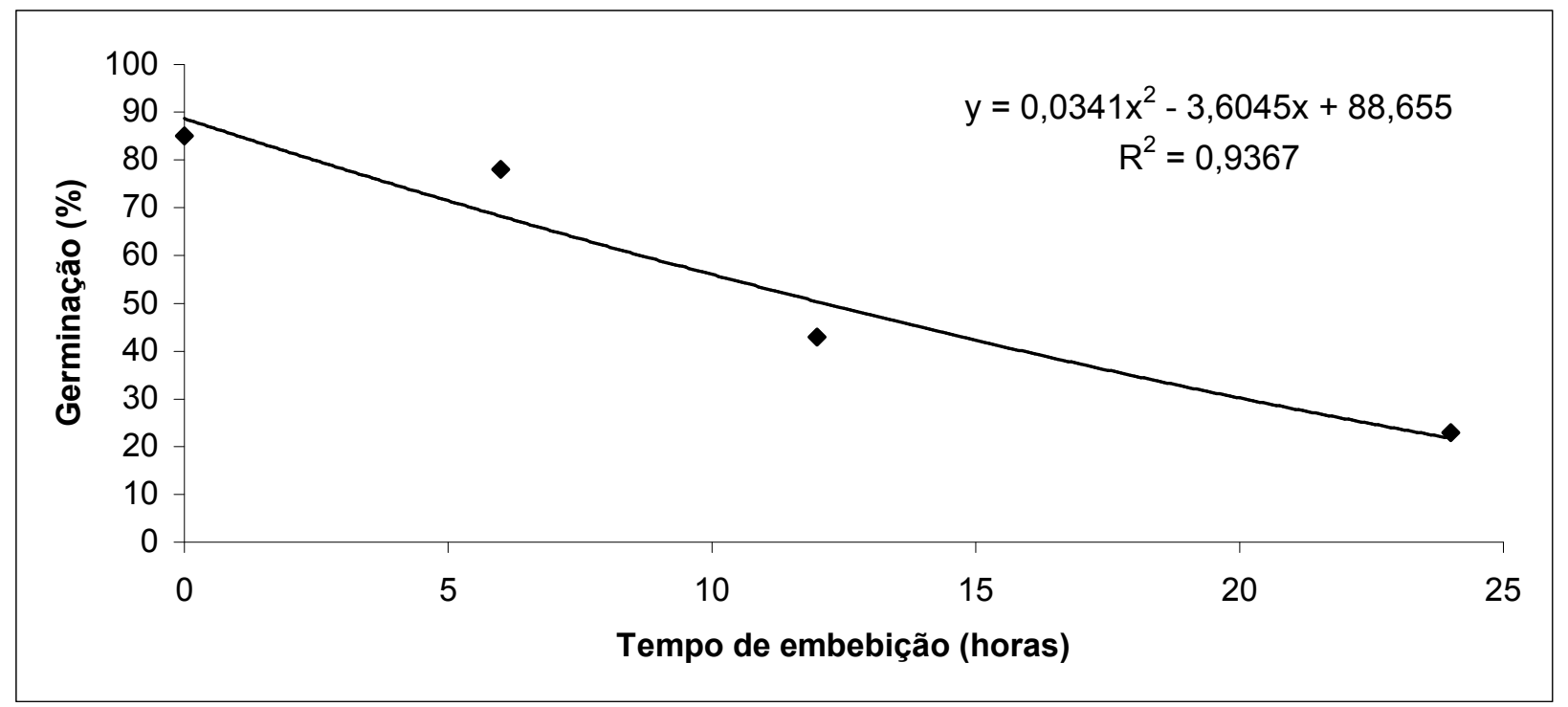

FIGURA 4. Germinação de sementes de Erythrina variegata L. submetidas à escarificação mecânica e posteriormente à embebição em água por diferentes períodos. Laboratório de Sementes, CCA - UFES. Alegre-ES, 2006. 


\section{CONCLUSÕES}

A caracterização morfológica dos frutos, sementes e plântulas fornece subsídios que facilitam o reconhecimento desta espécie;

Erythrina variegata L. dispensa a adoção de tratamentos para quebra de dormência, o que viabiliza e acelera a produção de mudas.

\section{AGRADECIMENTOS}

Os autores agradecem à Engenheira Agrônoma Marilda Torres Capucho, pela ajuda na condução dos trabalhos; à Chris Fantoni pelas ilustrações e à Maria de Fátima Tallon Matheus pela ajuda na coleta das sementes.

\section{REFERÊNCIAS}

ABREU, D.C.A.; KUNIYOSHI, Y.S.; NOGUEIRA, A.C.; MEDEIROS, A.C.S. Caracterização morfológica de frutos, sementes e germinação de Allophylus edulis (St.-Hil.) Radlk. Revista Brasileira de Sementes, Brasília, v.27, n.2, p.59-66, 2005a.

ABREU, D.C.A.; KUNIYOSHI, Y.S.; MEDEIROS, A.C.S.; NOGUEIRA, A.C. Caracterização morfológica de frutos e sementes de cataia (Drimys brasiliensis Miers. - Winteraceae). Revista Brasileira de Sementes, Brasília, v.27, n.2, p.67-74, 2005 b.

AÑEZ, L.M.M.; COELHO, M.F.B.; ALBUQUERQUE, M.C.F.; DOMBROSKI, J.L.D. Caracterização morfológica dos frutos, das sementes e do desenvolvimento das plântulas de Jatropha elliptica Müll. Arg. (Euphorbiaceae). Revista Brasileira de Botânica, São Paulo, v.28, n.3, p.563-568, 2005.

BAKER, H.G. Seed weight in relation to environmental conditions in Califórnia. Ecology, Victoria, v.53, n.6, p.998-1010, 1972.

BARROSO, G.M.; MORIM, M.P.; PEIXOTO, A.L.; ICHASO, C.L.F. Frutos e sementes: morfologia aplicada à sistemática de dicotiledôneas. Viçosa: UFV, 1999. 443p.

BIANCHETTI, A. Tecnologia de sementes de essências florestais. Revista Brasileira de Sementes, Brasília, v.3, n.3, p.27-46, 1981.

BORGES, E.E.L.; RENA, A.B. Germinação de sementes. In: AGUIAR, I.B.; PIÑA-RODRIGUES, F.C.M.; FIGLIOLIA, M.B. (Coord.). Sementes florestais tropicais. Brasília: ABRATES, 1993. p.83-135.

BRASIL. Ministério da Agricultura e Reforma Agrária. Regras para análise de sementes. Brasília: SNDA/DNDV/CLAV, 1992. 365 p.
CRUZ, E.D.; CARVALHO, J.E.U. Biometria de frutos e sementes e germinação de curupixá (Micropholis venulosa Mart. \& Eichler - Sapotaceae). Acta Amazônica, Manaus, v.33, n.3, p.389-398, 2003.

FERREIRA, R.A.; BOTELHO, S.A.; DAVIDE, A.C.; MALAVASI, M.M. Caracterização morfológica de fruto, semente, plântula e muda de Dipteryx alata Vogel - Baru (Leguminosae Papilionoideae). Cerne, Lavras, v.4, n.1, p.73-87, 1998.

FOWLER, J.A.P.; BIANCHETTI, A. Dormência em sementes florestais. Colombo: Embrapa Florestas, 2000. 27p. (Documento, 40).

GROTH, D.; LIBERAL, O.H.T. Catálogo de identificação de sementes. Campinas: Fundação Cargill, 1988. 183p.

LORENZI, H.; SOUZA, H.M.; TORRES, M.A.V.; BACHER, L.B. Árvores exóticas no Brasil: madeireiras, ornamentais e aromáticas. Nova Odessa: Plantarum, 2003.368p.

MAGUIRE, J.D. Speed of germination aid in selection and evaluation for seedling emergence and vigor. Crop Science, Madison, v.2, n.2, p.176-177, 1962.

MATOS, L.V.; CAMPELLO, E.F.C.; RESENDE, A.S.; PEREIRA, J.A.R.; FRANCO, A.A. Plantio de leguminosas arbóreas para produção de moirões vivos e construção de cercas ecológicas. Embrapa Agrobiologia (Sistemas de Produção), n.3 (versão eletrônica), 2005. Disponível em: <http:// www.cnpab.embrapa.br/publicacoes/sistemasdeproducao/ moirao/outras. htm>. Acesso em: 6 abr. 2006.

MAYER, A.M.; POLJAKOFF-MAYBER, A. The germination of seeds. London: Pergamon Press, 1989. 270p.

MELO, M.G.G.; MENDONÇA, M.S.; MENDES, A.M.S. Análise morfológica de sementes, germinação e plântulas de jatobá (Hymenaea intermedia Ducke var. adenotricha (Ducke) Lu \& Lang.) (Leguminosae-Caesalpinioideae). Acta Amazônica, Manaus, v.34, n.1, p.9-14, 2004.

PIÑA-RODRIGUES, F.C.M; COSTA, L.G.S.; REIS, A. Estratégias de estabelecimento de espécies arbóreas e o manejo de florestas tropicais. In: CONGRESSO FLORESTAL BRASILEIRO, 6, 1990, Campos do Jordão. Anais... São Paulo: SBS, 1990. p.676-684.

SAEG. Sistema para análises estatísticas e genéticas. (SAEG versão 7.1). Viçosa: UFV/FUNARBE, 1997.

SILVA, L.M.M.; MATOS, V.P. Morfologia da semente e da germinação de Erythrina velutina Willd. Revista Árvore, Viçosa, v.15, n.2, p.137-143, 1991.

SILVA, G.M.C.; SILVA, H.; ALMEIDA, M.V.A.; CAVALCANTI, M.L.F.; MARTINS, P.L. Morfologia do fruto, semente e plântula de mororó (ou pata-de-vaca) - Bauhinia forficata Link. Revista de Biologia e Ciências da Terra, Campina Grande, v.3, n.2, 2003. Disponível em: <http://www.uepb.edu.br/eduep/rbct/sumarios/ pdf/mororo.pdf >. Acesso em: 10 jun. 2006. 
SOUZA, L.A.G.; VARELA, V.P.; BATALHA, L.F.P. Tratamentos pré-germinativos em sementes florestais da Amazônia: VI Muirajuba Apuleia leiocarpa (Vog.) Macbride var. molaris Spr. ex Benth. (Leguminosae). Acta Amazônica, Manaus, v.24, n.1/2, p.81-90, 1994.
VIDAL, W.N.; VIDAL, M.R.R. Botânica: organografia. 4.ed. Viçosa: UFV, 2003. 124p.

\footnotetext{
$\star \dot{\Delta} \star \boldsymbol{t}$
} 